\title{
MIKE LEIGH, UN CINEASTA DISIDENTE
}

\section{Jon Urraza Intxausti}

Universidad del País Vasco / Euskal Herriko Unibertsitatea. Dpto. Comunicación Audiovisual. Doctorando

\section{Abstract}

Mike Leigh (Salford, Inglaterra 1943), como muchos otros cineastas de su generación se revelaba contra el alejamiento de la realidad del cine generalista, deseaba ver en la pantalla "gente viviendo como la gente real no como la gente en las películas", y este en definitiva, ha sido su compromiso artístico desde sus inicios hasta hoy, que los personajes de sus películas "parezcan gente viva auténtica" (Clements 1983, 25). Para conseguirlo, Leigh desarrolló su propio método de creación cinematográfica fundamentado en el trabajo creativo con los actores y esta manera de hacer cine, es la que le separa del sistema de la industria cinematográfica y le convierte en un auténtico disidente.

\section{Palabras clave: LEIGH, MIKE (1943 - ); CINE; VEROSIMILITUD; MÉTODO; INTERPRETACIÓN}

\section{MIKE LEIGH, A DISSIDENT FILMMAKER}

\section{Abstract}

Mike Leigh (Salford, England 1943), like many other filmmakers of his generation, revealed against the mainstream films' distance from reality, he wanted to see on the screen "people living as actual people not as the people in films" and this finally, has been his artistic commitment since the beginning, that characters in his films should "appear as authentic living people" (Clements 1983, 25). In order to accomplish this, Leigh developed his own film creation method based on a creative work with the actors and this way of filmmaking, is what pulls him apart from the film industry and become Leigh in an authentic dissident.

\section{Keywords: LEIGH, MIKE (1943 - ); CINEMA; VEROSIMILITUDE; METHOD; ACTING}

\footnotetext{
Urraza Intxausti, Jon. 2018. "Mike Leigh, un cineasta disidente". AusArt 6 (2): 113-122. D0I:10.1387/ausart.20373
}

\section{AUSART}




\section{LA VEROSIMILITUD EN LA INTERPRETACIÓN EN EL CINE}

La verosimilitud del relato es un concepto subjetivo que el espectador construye de acuerdo con lo que razona y siente cuando lo lee, ve y/o escucha. Platón habla de persuadir con el relato y "la persuasión depende de la verosimilitud" y Aristóteles define la verosimilitud como lo posible, lo que podría suceder. Siguiendo esta línea, Cristian Metz define lo verosímil como "lo que se parece a lo verdadero, pero sin serlo, algo que no es verdadero, pero tampoco demasiado diferente" ([1968] 1970, 28). Así, la evolución de lo verosímil cinematográfico hace referencia a las historias que se cuentan, sus personajes y también a los decorados que se muestran en los films, por eso cuando el público vio los documentales de la II. Guerra Mundial, observó "una puesta en escena tan colosal que dejaba en ridículo a los decorados de Cleopatra (De Mille 1934)" (Bazin [1958] 1966, 34). Esta evolución del cine que desde la irrupción del sonoro "puede decirse que no ha dejado de tender hacia el realismo" (ibíd., 447), lógicamente conlleva también una evolución en lo que se considera verosímil en la estética de la interpretación de los actores, y tanto es así que "el mismo público ha tenido mucho que ver con los cambios en la actuación cinematográfica. Se da cuenta con mucha rapidez de lo que es veraz y lo que no. Una vez que el público vio actuaciones como la de Henry Fonda en The Grapes of Wrath (Ford 1940), sintonizó con la diferencia entre el comportamiento basado en una realidad cuidadosamente observada y el que es más teatral y menos convincente" (Caine 2003, 32). Después de la guerra, la interpretación de actores formados en "El Método" fue decisiva en esta evolución, con películas como On the waterfront (Kazan 1954) "film que cambió la interpretación cinematográfica americana para siempre" (Ebert 1999).

Prácticamente al mismo tiempo, en Italia surge el Neorrealismo y pasa a ofrecer nuevas historias y nuevos personajes que difuminan a ojos del espectador las fronteras entre ficción y realidad. Si la evolución hacia el realismo en la interpretación cinematográfica en Hollywood vino de la mano de actores formados en El Método, el Neorrealismo italiano consiguió superar estas cotas de realismo, alejando el realismo de las convenciones y acercándolo a la realidad cotidiana en films como Roma città aperta (Rossellini 1945) o Ladri di biciclette (De Sica 1948). De este modo, trabajando en localizaciones reales con actores sin experiencia cinematográfica, con no actores o amalgamando actores con no actores, lograron un resultado en pantalla donde "el efecto total de la película (Roma città aperta) es una sensación de experiencia real" (Crowther 1946). Además, tras la II Guerra Mundial, los avances tecnológicos 
facilitaron la grabación en exteriores con cámaras portátiles y equipos de grabación de sonido sincrónico, esto posibilitó el nacimiento de nuevos movimientos cinematográficos que buscaban ofrecer nuevos verosímiles al espectador, movimientos como el cinema vérité, que pretendía "registrar los hechos de forma neutral (...) y presentar simplemente una parte de la vida" (Bordwell \& Thompson [1979] 2010, 406). El Free Cinema británico con jóvenes autores como Richardson, Anderson o Reisz, a los que se denominó The Angry Young Men, porque se revelaban contra el distanciamiento de la realidad del cine tradicional y buscaban hacer cine socialmente comprometido, reivindicativo, libre y espontaneo. En Francia Godard, Truffaut etc. revolucionaron el cine con la Nouvelle Vague y en la misma época en Estados Unidos nació el cine independiente de la mano de directores como John Cassavetes.

Hoy podemos afirmar que "en la segunda mitad del siglo XX (y lo que llevamos de XXI), el estilo preponderante en el actor de cine ha sido el naturalismo" (Nacache 2006,145 ) y en esta evolución hacia la simplificación y la invisibilidad de la interpretación, también contribuyó la irrupción de la televisión; la pantalla era pequeña comparada con la de cine y "el primerísimo primer plano se popularizó, la más ligera exageración de la expresión facial era perceptible, incluso desagradable, así que los actores tuvieron que aprender a simplificar las expresiones físicas" (Barr [1982] 1997, 24). Posteriormente, actores y directores forjados en televisión como Lumet, Frankenheimer o Jewison saltaron al cine trasladando su estilo televisivo y su estética de la interpretación. Hoy en día, en la llamada 'época dorada de la televisión', con el éxito de series de gran calidad como The Sopranos (D. Chase, 1999) o The Wire (D. Simon, 2002) se puede afirmar que el hecho de que una ficción dramática sea para la televisión o para el cine, no condiciona una diferencia en la estética de la interpretación, y finalmente, en todos los medios basados en la cámara, "la actuación simple, sincera y centrada sobre todo en escuchar ha pasado a ser el planteamiento dominante" (Barr [1982] 1997, 24).

El espectador actual acostumbra a ver en su cada vez más grande pantalla de televisión, películas, series y documentales, pero también reality-shows y vídeos anónimos que buscan persuadirle de que han registrado lo sucedido delante de la cámara en una suerte de grado cero de mirada. Consecuentemente, al espectador se le hace cada vez más difícil aceptar la más mínima diferencia entre las 'personas reales' que aparecen en televisión y los personajes de una ficción dramática con pretensiones realistas. Aparentemente fundamentamos nuestro 'índice de rechazo' en nuestra experiencia vicaria como observadores de la realidad, de la realidad que nos rodea y de 'la realidad' 
que vemos a través de la pantalla, pantalla que sin duda "ha modificado nuestro sentido de la verosimilitud en la interpretación" (Bazin [1958] 1966, 260). Pero a la hora de situar los límites de dicha verosimilitud, las convenciones del género también inciden y mucho, de hecho, muy a menudo la experiencia previa más importante "para percibir la forma, no es la experiencia de la vida cotidiana, sino los encuentros anteriores con obras que presentan convenciones similares" (Bordwell \& Thompson [1979] 2010, 47), y la comparación con estas obras anteriores condiciona nuestra aceptación o rechazo. Como consecuencia de esto, el cine, independientemente que sea realista o fantasioso, "no representa todo lo posible, todos los posibles, sino sólo los posibles verosímiles" (Metz [1968] 1970, 19).

Si consideramos que "el factor más importante para crear realismo es probablemente la interpretación" (Bordwell \& Thompson [1979] 2010, 433) y que el resultado de la interpretación de los actores a ojos del espectador también sufre una evolución, concluiremos que cuando el espectador alcanza una etapa de conocimiento avanzado y se convierte en experto, ha construido su conocimiento en base a unas convenciones que ha aceptado y asimilado, también en lo que se refiere a la interpretación. Por tanto, podemos afirmar que "la motivación 'realista' depende de lo que parece natural a alguien versado en convenciones específicas" (Bordwell [1985] 1996, 149), es decir, que "el símbolo se convierte en norma" y lo verosímil se define "por su fin, que es, la censura o represión" (Burgelin [1968] 1970, 162). De este modo, la construcción y evolución de lo verosímil cinematográfico, de lo que es decible y lo que no en un film, es mutable. Y en esta evolución permanente, cuando las convenciones aceptadas por cineastas, críticos y espectadores son transgredidas, o bien establecen nuevos verosímiles o de lo contrario son rechazadas. Así, en el siglo XVIII "mucha gente no acepto la representación de Garrick del Rey Lear porque pensaba que era excesivamente realista y no se atenía al nivel clásico de Shakespeare" (Hethmon 1965, 265), y en cambio, "la aclamada interpretación 'realista' de Marlon Brando en On the waterfront, nos parece muy estilizada hoy en día" (Bordwell \& Thompson [1979] 2010, 146).

Como consecuencia de este toma y daca entre lo que el cine propone al espectador, y lo que éste, una vez aceptado ese nuevo verosímil, exige a ulteriores films, el espectador "exige hoy creerse lo que ve" (Bazin [1958] 1966, 45) y en los escenarios auténticos espera que "los personajes sean tan reales como los que ven en los documentales" (Rabiger 1987, 341), pero cuando deja de creer en el actor, aborta la 'suspensión de su incredulidad' (Zunzunegui \& Zumalde 2014) y la falta de credibilidad del actor pasa a afectar a toda la película, ya 
que "cuando un actor simula el miedo al naufragio, sobre el puente de un navío verdadero batido por una verdadera tempestad. No creemos ni en el actor, ni en el navío, ni en la tempestad" (Bresson 1979, 25). Definitivamente, actuar para la pantalla hoy en día es "en mucha mayor medida una cuestión de 'ser' que de 'interpretar' (Caine 2003, 32).

\section{MIKELEIGH: TRANSGRESIÓN, DISIDENCIA Y MÉTODO}

Cineastas como Mike Leigh buscan "la disolución o el ablandamiento progresivo de lo Verosímil cinematográfico y el enriquecimiento progresivo de lo decible fílmico (vivido como "deseo de decirlo todo»)" (Metz [1968] 1970, 30), porque lo verosímil es al fin y al cabo una convención mutable que evoluciona con el tiempo. Esta liberación de lo verosímil cinematográfico provoca la "reactualización de algunos posibles que están en la vida, pero que su previa exclusión de las obras anteriores en virtud de lo verosímil, había hecho olvidar" (ibíd..., 25) y como consecuencia, los nuevos sistemas que presentan estas "obras artísticas poco comunes, pueden proporcionar nuevas convenciones y así crear nuevas expectativas" (Bordwell \& Thompson [1979] 2010, 47).

Leigh desde sus inicios ha tratado de cambiar lo decible cinematográficamente en lo que a las presencias humanas y su comportamiento se refiere, y si bien es cierto que el público acepta un nuevo verosímil cuando le parece 'más real' que los anteriores, este proceso de reactualización de los posibles de la vida al cine de ficción no es ni mucho menos sencillo. Mike Leigh sabe que mientras que una realidad concreta existe porque existe, independientemente de que sea filmada o no, cuando lo que se filma es ficción, dicha "realidad ficticia existe sólo en virtud del hecho de que se narra" (Bordwell [1985] 1996, 11), y por ello, la "noción indisoluble de lo Real que observamos en Leigh" (Isaacs 2006, 18) está condicionada para el espectador por las convenciones del género y su verosimilitud preestablecida. Por ese motivo "lograr la sensación de una realidad preexistente motiva todo lo que Leigh hace" -(Brunette, citado en Leigh 2000, 32), porque de este modo, pretende liberarse de dichas convenciones por haber creado una 'realidad' más cercana "a la sensación de cómo la vida es vivida realmente” (Carney \& Quart 2000, 67). 
Leigh no acepta tener que limitarse a los posibles verosímiles, no está dispuesto a modificar la realidad para ajustarse a las convenciones del género tal y como se hace a menudo, incluso en films de ficción que se basan en hechos reales. Leigh desea "reflejar las cosas como son" (O'Sullivan 2011, 148) y por eso, critica que aun hoy "el cine no nos muestra como es la gente realmente" (Foundas 2008). A la búsqueda de este objetivo, a veces transgrede las convenciones aceptadas por el espectador, y es entonces cuando sus films son atacados, "porque fallan al dar vida a cierto código restrictivo de realismo, código al cual él nunca ha solicitado inscribirse" (O'Sullivan 2011, 1). En ocasiones de hecho, es acusado de exagerar o caricaturizar determinados personajes convirtiéndolos en patrones de conducta de una determinada clase social, como los ricos de High Hopes (Leigh 1988) por ejemplo. Leigh argumenta en este sentido, que si observas a la gente y "pones en pantaIla características de comportamiento con absoluta precisión, unas personas parecerán más extravagantes que otras", y utiliza como ejemplo un suceso que al parecer ocurrió durante la entrevista, parece ser que la camarera se patinó justo detrás de la silla donde estaba sentado Leigh y se cayó al suelo, y dice que si hiciera una película sobre la entrevista incluiría la caída, "porque sucedió así. Pero la gente lo entendería como un intento de establecer un patrón de comportamiento hacia la camarera. Pero realmente, sucedió porque sucedió" (Leigh 2000, 46).

Mike Leigh en definitiva, siempre ha sido un cineasta disidente del cine más generalista por los temas que trata, por tratarlos a través de retratos sumamente concretos de personajes anónimos en su ámbito privado y familiar, como en Four days in July (Leigh 1985) donde su representación del conflicto norirlandés queda restringida al ámbito doméstico y familiar de dos mujeres, una católica y la otra protestante, durante los últimos cuatro días de sus respectivos embarazos. Leigh es un disidente porque hace películas en las que aparentemente no pasa demasiado, en las que los personajes no luchan por conseguir una meta en un tiempo limitado como en el cine mainstream; porque plantea finales abiertos que no concluyen con "visionarios modelos de conducta" sino que simplemente muestra a "unos personajes viviendo a lo largo de una serie de acontecimientos temporales" (Carney \& Quart 2000, 76) que acaban dejando la "sensación de que esas personas siguen ahi" (O'Sullivan 2011, 160). Pero lo que realmente convierte a este cineasta en un auténtico disidente, es que para intentar conseguir sus objetivos artísticos, desarrolla un método de creación propio que combina el proceso de escritura con el proceso ensayos, proceso en el que partiendo desde cero, construye con los actores una 'realidad' para después decidir cómo registrarla. Este compromiso incorruptible de Leigh con un método de trabajo propio que le posibilite la con- 
secución de sus objetivos artísticos, es lo que le hace chocar de raíz con la doctrina dominante de la industria cinematográfica.

Mike Leigh destierra de la mente de los actores: "la exigencia de ofrecer resultados desde el primer día, les libera, como dice Leigh, "de la idea de tener que ser interesantes, divertidos o tristes', les libera de todo 'salvo de tener que ser reales' "(Watson 2004, 29)y para intentar conseguirlo comienza a trabajar individualmente con cada actor para crear su personaje desde la observación de personas reales como trampolín creativo para desarrollar un "personaje que provendrá de un ambiente especifico localizable, social, educacional, cultural y económicamente" (Clements 1983, 22), ya que "no hay un cineasta más comprometido con la individualidad de sus personajes o más crítico con personajes que abrazan identidades genéricas" (Carney \& Quart 2000, 250). Después, se trabajan las relaciones entre personajes de manera experiencial, en largos procesos de improvisación a tiempo real, las primeras citas de una pareja o el primer día laboral entre unos compañeros de trabajo, por ejemplo, con el fin de investigar y desarrollar dichas relaciones en el tiempo desde la experiencia vivida. A través de estas improvisaciones que no aparecerán en la película, las relaciones van cogiendo cuerpo y se van generando vivencias comunes que llenaran la 'mochila' emocional de cada personaje. De esta manera, los personajes en el cine de Leigh se construyen desde la individualidad, pero se muestran al espectador a través del "establecimiento de relaciones con otros personajes" (Brecht [1947] 2004, 267), como en Another Year (Leigh 2010) donde vemos a una serie de personajes que padecen de soledad únicamente en los instantes en los que se relacionan socialmente. Una vez construidos los personajes y las relaciones, Leigh comenzará a plantear situaciones para que los actores improvisen desde su personaje, cuyo comportamiento estará condicionado y limitado por todo el bagaje que habrá ido generándose en cada uno. Estas situaciones estructurarán la narración y las escenas se terminarán de fijar en las localizaciones reales donde transcurrirá el argumento. De esta manera, Leigh estructurará y destilará el film, pero nunca entregará "a los actores un guion convencional con los diálogos escritos. ¡Nunca jamás!” (Leigh, en Ho 2014). En definitiva, toda su creación fílmica la desarrolla en base a un elaborado método de dirección de actores que abarca todo el proceso y que como consecuencia obtiene un resultado, una filmografía, en la que el trabajo de los actores y la estética de la interpretación son fundamentales para conseguir "personajes que son tan individualizados y verdaderos que, como la gente en el mundo real, sus emociones no son predecibles o prefijadas" (Carney \& Quart 2000, 10). 
Por todo esto sin duda podemos afirmar que "nada en la práctica artística de Leigh parece más vanguardista que su profundo compromiso con un método de radical experimentación" (Watson 2004, 14). Método que le aparta de la industria y le dificulta muchísimo la obtención de financiación. Aun así, ha sido nominado en cinco ocasiones al Oscar al mejor guion y entonces, la academia de Hollywood, de acuerdo con sus convencionales y asumidas reglas de creación cinematográfica, le ha solicitado el guion escrito. Leigh en esa tesitura, se ha visto obligado a transcribir el guion del film ya terminado con el fin ser reconocido por las instituciones de la industria fílmica. Esto ilustra lo amplia que es la distancia entre el punto de vista de Leigh sobre cómo hacer cine y el modus operandi que impone la industria. Lo irónico es que si Leigh hubiera jugado según las reglas, aceptando escribir el guion de antemano, es posible que no hubiera conseguido hacer un film tan excepcional como para ser reconocido de esta manera.

Si consideramos que la disidencia es el desacuerdo o disconformidad de alguien respecto de las doctrinas, creencias, sistema, etc., que sostiene el colectivo al que pertenece; definitivamente, Mike Leigh es un auténtico disidente que a sus 75 años, sigue tratando de transgredir convenciones para actualizar los posibles verosímiles del cine a través de un compromiso absoluto con un método de creación propio que le separa de la industria cinematográfica y le convierte en un creador totalmente independiente.

\section{Referencias}

Arrieta Urtizberea, Agustin. 2017. "Fikzioa, ezagutza eta zentsura". Campusa. 2 feb. https:// www.ehu.eus/eu//-/n_20170210-cathedra-agustin-arrieta

Barr, Tony. (1982) 1997. Actuando para la cámara: Manual para cine y TV. Con ejercicios de Eric Stephan Kline; traducción de Marta Heras. Madrid: Plot

Barthes, Roland, et al. (1968) 1970. Lo verosímil. Traducción de Beatriz Dorriots. Buenos Aires: Tiempo Contemporáneo (Originalmente: "Recherchessémiologiques, le vraisemblable", Communications 11)

Bazin, André. (1958) 1966. ¿Qué es el cine? Versión española por José Luis López Muñoz. Madrid: Rialp

Boal, Augusto. (1982) 2001. Juegos para actores y no actores. Traducción Mario Jorge Merlino Tornini. Barcelona: Alba

Bordwell, David \& Kristin Thompson. [1979] 2010. El arte cinematográfico. Traducción de Yolanda Fontal Rueda. Barcelona: Paidós

Bordwell, David.[1985] 1996. La narración en el cine de ficción. Traducción de Pilar Vázquez Mota.Barcelona: Paidós 
Brecht, Bertold. (1947) 2004. Escritos sobre teatro. Traducción, selección y prólogo, Genoveva Dieterich. Barcelona: Alba

Bresson, Robert. 1979. Notas sobre el cinematógrafo. Traducción de Saúl Yurkiévich. México DF: ERA

Burgelin, Olivier. (1968) 1970. "Intercambio y deflación en el sistema cultural". En Lo verosimil. Roland Bartheset al., traducción de Beatriz Dorriots, 145-168. Buenos Aires: Tiempo Contemporáneo

Caine, Michael. 1990. Actuando para el cine. Traducción de Marta Heras.Madrid: Plot Applause Theatre

Carney, Ray \& Leonard Quart. 2000. The films of Mike Leigh: Embracing the world. Cambridge: Cambridge University

Cassavetes, John. 2001. Cassavetes por Cassavetes. Ray Carney, ed.; traducción de Daniel Najmías. Barcelona: Anagrama

Català Domènech, Josep Maria. 2001. La puesta en imágenes:Conceptos de dirección cinematográfica. Barcelona: Paidos

Clements, Paul. 1983. The improvised play: The work of Mike Leigh. London: Methuen

Coveney, Michael. 1996. The world according to Mike Leigh. London: Harper Collins

Crowther, Bosley. 1946."How Italy resisted".The New York Times, 26 feb. (facsímil digital) https://www.nytimes.com/1946/02/26/archives/the-screen-how-italy-resisted.html

Ebert, Roger. 1999.“On the Waterfront”. Rogerebert.com, web personal del autor. 21 mar. http:// www.rogerebert.com/reviews/great-movie-on-the-waterfront-1954

Gaudreault, André \& François Jost. 1995. El relato cinematográfico. Traducción de Núria Pujol. Barcelona: Paidós

Hagen, Uta. (1991) 2002. Un reto para el actor. Traducción: Elena Vilallonga. Barcelona: Alba

Hethmon, Robert H. 1965. El Método del Actor's Studio. Conversaciones con Lee Strasberg. Traducción, Charo Álvarez y Ana María Gutiérrez-Cabello.Madrid: Fundamentos

Isaacs, Bruce. 2006. "Film cool: Towards a new film aesthetics". Tesis University of Sydney.

Kagan, Jeremy. 2005. La mirada del director. Entrevistas con directores de cine. Traducción: Marta Heras. Madrid: Plot

Layton, William. 1990. ¿Por qué? Trampolín del actor. Con la colaboración de José Carlos Plaza\& Juan Antonio López Esteve.Madrid: Fundamentos

Leigh, Mike. 2000. Mike Leigh: Interviews. Edited by Howie Movshovitz. Jackson MS: University of Mississippi

Meisner, Sanford \& Dennis Longwell. 1987.Sanford Meisner on acting. Introduction by Sydney Pollack. New York: Vintage Books

Metz, Christian. (1968) 1970. "El decir y lo dicho en el cine: ¿Hacia la decadencia de un cierto verosímil?". En Lo verosimil. Roland Bartheset al., traducción de Beatriz Dorriots, 17-30. Buenos Aires: Tiempo Contemporáneo

Monterde Lozoya, José Enrique. 2001. "Realidad, realismo y documental en el cine español". En Imagen, memoria y fascinación: Notas sobre el documental en España, Josep Maria Català, Josetxo Cerdán, Casimiro Torreiro, coords., 15-26 Madrid: Ocho y Medio 
Nacache, Jacqueline. 2003. El actor en el cine. Traducción de Carla Revuelta. Barcelona: Paidós

O'Sullivan, Sean. 2011. Mike Leigh. Urbana, IL: University of Illinois

Rabiger, Michael. 1987. Dirección de cine y video: Técnica y estética. Traducido por Carmen Bris Morillas. Madrid: Instituto Oficial de Radiotelevisión Española.

Ruiz, Borja. 2008. El arte del actor en el siglo XX: Un recorrido teórico y práctico por las vanguardias. Bilbao: Artezblai

Stanislavski, Konstantin. (1938) 2003.El trabajo del actor sobre sí mismo en el proceso creador de la vivencia. Tradución y notas de Jorge Saura. Barcelona: Alba

Swenson, Leland C. 1980.Teorías del aprendizaje: Perspectivas tradicionales y desarrollos contemporáneos. Traducción de Luis Nicolás Justo. Barcelona: Paidós

Watson, Garry. 2004. The cinema of Mike Leigh: A sense of the real. London: Wallflower

Zunzunegui Díez, Santos \& Imanol Zumalde Arregi. 2014."Guía para escépticos avatares de la doble lectura modélica del discurso documental". Signa 23: 843-65

\section{Filmografía citada}

Chase, David. 1999. The Sopranos. Home Box Office (HBO)

De Sica, Vittorio. 1948. Ladri di Biciclette. Produzioni De Sica (PDS)

Ford, John. 1940. The Grapes of Wrath. Productor, Darryl F. Zanuck. 20th Century Fox

Foundas, Scott. 2008."Mike Leigh: Moments". Regis dialogue at Walker Art Center, Oct. 15

Ho, Jude. 2014. "The one and only Mike Leigh". Documental BBC (Imagine, season 24, episode 5), 1:40:00.

Kazan, Elia. 1954. On the Waterfront. Columbia Pictures

Leigh, Mike. 1985. Four days in July. British Broadcasting Corporation (BBC)

- 1988. High Hopes. British Screen Productions / Channel Four Films

- 2010. Another Year. Film4 / Focus Features / Thin Man Films / UK Film Council

Rossellini, Roberto. 1946. Roma città aperta. Excelsa Films

Simon, David \& Joe Burns. 2002. The Wire. Home Box Office (HBO)

(Artículo recibido: 10-11-18; aceptado: 23-12-18) 